\title{
Legal vs. ethical obligations - a comment on the EPSRC's principles for robotics
}

\section{Vincent C. Müller}

To cite this article: Vincent C. Müller (2017) Legal vs. ethical obligations - a comment on the EPSRC's principles for robotics, Connection Science, 29:2, 137-141, DOI:

10.1080/09540091.2016.1276516

To link to this article: http://dx.doi.org/10.1080/09540091.2016.1276516

曲 Published online: 19 Apr 2017.

Submit your article to this journal $\pi$

Џll Article views: 131

Q View related articles $₫$

View Crossmark data $\nearrow$ 


\title{
Legal vs. ethical obligations - a comment on the EPSRC's principles for robotics
}

\author{
Vincent C. Müller (1) a,b

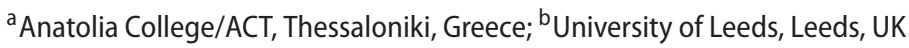

\begin{abstract}
While the 2010 EPSRC principles for robotics state a set of five rules of what "should" be done, I argue they should differentiate between legal obligations and ethical demands. Only if we make this difference can we state clearly what the legal obligations already are, and what additional ethical demands we want to make. I provide suggestions how to revise the rules in this light and how to make them more structured.
\end{abstract}

\section{ARTICLE HISTORY}

Received 20 June 2016

Accepted 21 December 2016

\section{KEYWORDS}

Robot ethics; robot law; principles of robotics; legal obligation; killer robots

\section{The principles}

Allow me to quote the short statements of the "Principles for designers, builders and users of robots" (EPSRC, 2010) in full:

(1) Robots are multi-use tools. Robots should not be designed solely or primarily to kill or harm humans, except in the interests of national security.

(2) Humans, not robots, are responsible agents. Robots should be designed \& operated as far as is practicable to comply with existing laws \& fundamental rights \& freedoms, including privacy.

(3) Robots are products. They should be designed using processes which assure their safety and security.

(4) Robots are manufactured artefacts. They should not be designed in a deceptive way to exploit vulnerable users; instead their machine nature should be transparent.

(5) The person with legal responsibility for a robot should be attributed.

\section{Legal vs. ethical}

The first four EPSRC principles are formulated as one factual statement, plus a rule what "should" be done; and the fifth principle only has the rule. (The EPSRC principles also feature seven "high-level messages" that formulate more general "things to remember". I will not discuss these here in any detail.). The formulation as rules is a common and useful way of presenting ethical demands - though it also has well-known problems, esp. in cases where 
rules conflict. I agree with the general direction of the principles, so my suggestion is to revise them, rather than to start afresh. In this comment, I will focus on one area for revision only. In particular, I will not comment on whether the use of purportedly factual statements is conducive to the aims, and whether the principles are ethically correct. I will, however, indicate where I see problems with the impression that the principles give, of representing universally accepted ethical rules.

My main worry is that the principles fail to distinguish between legal and ethical rules. This is unusual since we normally think that these two are logically independent: If some particular action is legal, it may still be unethical; if some particular action is ethical, it may still be illegal - it is not the case that an action is ethical if and only if it is legal. For rules, this means, if we accept an ethical rule, this does not imply that there is or should be a legal rule; conversely if we accept a legal rule, this does not imply that there is or should be an ethical rule (though in an ideal state we would hope for law to be based on ethical grounds). The failure to make this distinction has two consequences in our case: (1) the principles present legal obligations as ethical demands, which is practically misleading; a reader of the principles may consider whether or not to follow the rule, while in their jurisdiction they are already legally forced to follow it, and risk punishment if they do not. (2) The principles also fail to present ethical demands that are not already legal demands - this unduly limits the scope of the document, which could state demands that go beyond the already existing law. In order to improve the principles I suggest two steps.

Terminological note: I speak of legal obligations and ethical demands; this is just a convention to avoid confusion between the two.

\section{Legal}

The principles should clearly state what the basic legal obligations are, and for whom. For this purpose, legal obligations must be differentiated for different agents and, particularly, for different economic systems: those who use robotics (a) for-profit and (b) not for-profit, for example, in research and sharing. Furthermore, they should indicate that we do not think the current legal obligations in the UK are clearly unethical, so we assume that agents in robotics have an obligation to adhere to these legal obligations. Otherwise the principles should indicate whether a revision of current law is envisaged - in my opinion, a good candidate would be the "The Investigatory Powers Act" (UK Parliament, 2016). Finally, we should indicate whether we consider the principles to be relevant for the UK only, or to go beyond.

To put this in terms of comments on the individual principles: concerning principle 1, there are severe legal restrictions on making and selling a product that is a weapon; violating these is a criminal offense. The "softening" through the phrase of "except in the interests of national security" re-introduces robotic weapons for state agents - thus principle 1 essentially re-states the current legal situation in European countries: weapons of war are limited to state agents, while some small firearms (e.g. handguns and hunting rifles) and other weapons (e.g. knives) can be licensed for use by private persons (Alpers, Rossetti, \& Wilson, 2016; Council of the European Communities, 1991). So, at this point we should state what the legal situation is and whether we want to make special restrictions on the use of robots as weapons. 
Given that the design of weapons "solely or primarily to kill or harm humans" (principle 1) is legal and arguably ethical, we need a special argument why the design and use of robotic weapons, should be ethically wrong. The discussion about this issue usually concerns autonomous robotic weapons, or "killer robots" (ICRAC, 2010; Leveringhaus, 2016; Müller, 2016; Sparrow, 2016). If principle 1 considers only weapons of war then it should say so and mention that this is already the legal situation. If it wants a more general restriction on robotic weapons, for example, disallowing use by police, then it goes beyond current law and generally accepted ethics. I thus wonder whether principle 1 it has a place here, esp. as a first in the list. It is understandable that robotics wants to keep its hands clean by staying away from weapons, but that may well not be possible or even ethical.

Principle 2 explicitly puts laws, fundamental rights and freedoms in one bag - which is what I recommend we do not do. (I also think we do not need the awkward "freedoms" at all, since these are rights.) It states that design and operation must "comply with existing laws", which is trivially true, but this is prefixed with the phrase "as far as is practicable". Given that we cannot normally argue that we will comply with the law only as far as it is "practicable", this remark needs some explanation; or removal. As in the current principle 1, the "fact" stated at the outset "Humans, not robots, are responsible agents" has only a rather loose relation to the demands made afterwards. And, again, in principle 2, we should state what the legal protection obligations are, for example, in UK and EU law, and then indicate what further ethical demands we want to make. I tend to think this principle should become principle no. 1, as it is more fundamental than the others.

Principle 3 states that robots are products - but some robots are not "products" in the legal sense, because they are not sold commercially. When they are, the whole barrage of product legislation applies to them, in particular the manufacturer is liable for damages with "intended use", has to grant warranty, etc. Again, this should be stated. At this point the legal obligations of for-profit and not for-profit manufacture and use differ.

Principle 4 on not making deceptive "manufactured artefacts" concerns all known robots, since they are made by intentional action for certain purposes - they do not grow or come about accidentally. Usually, the ethical obligation not to deceive other humans is not a legal one, but in the cases of financial gain, as when selling a product, there is already a legal obligation of non-deception. The legal situation differentiates between manufacturer's, seller's and consumer's obligations. What the authors have in mind when they talk about "machine nature" is presumably the obligation not to present a robot as a non-robot, for example, a living being - but I am not sure why this particular issue is singled out among deceptions (rather than deceptive advertisement, etc.). Avoiding that particular deception of users is not a legal obligation at this point in time and, given robot hardware, it will be a rare case in the foreseeable future.

The demand in principle 5 that "The person with legal responsibility for a robot should be attributed" is a clear case of re-stating a legal obligation - though "person" should be "legal person" here. A "legal person" can be either a "natural person" (like you and me) or a juridical person (like a company or a state). Also, what is loosely called "responsibility" here really needs a differentiation between legal liability (criminal and civil) and moral responsibility for actions ... and of course there is significant literature on both (e.g. Eshleman, 2014). These two distinctions may be useful for a re-formulation of the principles.

As above, legal liability is not something that needs to be demanded: legal persons are liable for their actions and the law will determine how. Having said that, it is doubtful that 
"the person" is only one for a particular robot at a particular time, given that user's, seller's and manufacturer's responsibility will exist at the same time. The manufacturer will typically be a company, that is, a juridical person.

If "responsibility" means ethical responsibility, then the difference between "user" and "system" actions would need to be used and some mention of "autonomy" may be made. We have argued at some length that even autonomous robots do not take ethical responsibility away from humans (Simpson \& Müller, 2016), so whether we like it or not, legal and ethical responsibility remains in place. Even for legal liability it seems that the existing sophisticated framework for attribution may well be sufficient to cover problematic cases robots are not the first products where things can go wrong while it is not easy to identify a natural person that is liable.

Overall, the principles should state clearly what the current legal situation is, in a particular jurisdiction, and whether that situation needs to change because the authors see further issues. Also whether they see ethical demands that they do not expect or wish to become legal obligations.

\section{Ethical}

As we have seen, the five principles effectively re-state some legal demands that already exist, and this should be made clear. Furthermore, the principles should name ethical demands that we want to make that go beyond these legal demands. These additional ethical demands should be explained with the help of the basic theoretical tools available, for example, mentioning basic universal rules or values (e.g. non-deception and respect of privacy), and considerations of utility in consequentialist ethics. This would also help to clarify the relation between legal obligations and moral responsibility. I suspect that there will be such responsibilities for the designers of robots, for example, that they are not deceptive and will design safe products (principles 3 and 4) and that regulation be put in place that allows clearer identification of ethical responsibility. Finally, the principles should state open ends, and the double open-endedness of this exercise: there are some things we know about but that have not been resolved in these guidelines; also, we do not yet know what societal impact robotics may have, and what problems will surface in the future. Finally, as Tony Prescott pointed out in the meeting, we do not know whether we will want to allocate ethical responsibility to non-natural agents, one day.

\section{Acknowledgement}

I am grateful to Tony Prescott for the invitation to the 2016 AISB workshop and the opportunity to develop some ideas. I am grateful to the anonymous reviewers, esp. the one who provided very detailed comments. I now chair the euRobotics topics group on "ethical, legal and socio-economic issues" (http://www.pt-ai.org/TG-ELS/) and we appreciate the opportunity for cooperation with the AISB and EPSRC.

\section{Disclosure statement}

No potential conflict of interest was reported by the author. 


\section{ORCID}

Vincent C. Müller (D) http://orcid.org/0000-0002-4144-4957

\section{References}

Alpers, P., Rossetti, A., \& Wilson, M. (2016). European Union - gun facts, figures and the law. Sydney School of Public Health. Retrieved December 13, 2016, from http://www.gunpolicy.org/firearms/ region/european-union

Council of the European Communities. (1991). 91/477/EEC - European Firearms Directive. EUR-Lex. Retrieved June 18, 1991, from http://data.europa.eu/eli/dir/1991/477/oj

EPSRC. (2010). Principles of robotics: Regulating robots in the real world. Retrieved from https://www. epsrc.ac.uk/research/ourportfolio/themes/engineering/activities/principlesofrobotics/

Eshleman, A. (2014). Moral responsibility. In E. N. Zalta (Ed.), Stanford encyclopedia of philosophy. Palo Alto, CA: Stanford University. Retrieved from https://plato.stanford.edu/entries/moralresponsibility/

ICRAC. (2010). Berlin statement. International Committee for Robotic Arms Control. Retrieved from http://icrac.net/statements/

Leveringhaus, A. (2016). Ethics and autonomous weapons. London: Palgrave Pivot.

Müller, V. C. (2016). Autonomous killer robots are probably good news. In E. Di Nucci \& F. Santoni de Sio (Eds.), Drones and responsibility: Legal, philosophical and socio-technical perspectives on the use of remotely controlled weapons (pp. 67-81). London: Ashgate.

Simpson, T. W., \& Müller, V. C. (2016). Just war and robots' killings. The Philosophical Quarterly, 66(263), 302-322. doi:10.1093/pq/pqv075

Sparrow, R. (2016). Robots and respect: Assessing the case against autonomous weapon systems. Ethics \& International Affairs, 30(1), 93-116.

UK Parliament. (2016). Investigatory powers act. The National Archives. Retrieved November 29, 2016, from http://www.legislation.gov.uk/ukpga/2016/25/contents/enacted/data.htm 